\title{
Evaluating Industry 4.0 Technology Application in SMEs: Using a Hybrid MCDM Approach
}

\author{
Shih-Chia Chang ${ }^{1}$, Hsu-Hwa Chang ${ }^{2}$ and Ming-Tsang $\mathrm{Lu}^{1, *}$ \\ 1 College of Management, National Taipei University of Business, Taipei 10051, Taiwan; chang@ntub.edu.tw \\ 2 Department of Business Administration, National Taipei University of Business, Taipei 10051, Taiwan; \\ hhchang@ntub.edu.tw \\ * Correspondence: mingtsang@ntub.edu.tw; Tel.: +886-2-2322-6325
}

Citation: Chang, S.-C.; Chang, H.-H.;

Lu, M.-T. Evaluating Industry 4.0

Technology Application in SMEs:

Using a Hybrid MCDM Approach.

Mathematics 2021, 9, 414. https://

doi.org/10.3390/math9040414

Academic Editor: Francisco

Javier Cabrerizo-Lorite

Received: 4 January 2021

Accepted: 6 February 2021

Published: 20 February 2021

Publisher's Note: MDPI stays neutral with regard to jurisdictional claims in published maps and institutional affiliations.

Copyright: (c) 2021 by the authors. Licensee MDPI, Basel, Switzerland. This article is an open access article distributed under the terms and conditions of the Creative Commons Attribution (CC BY) license (https:// creativecommons.org/licenses/by/ $4.0 /)$.
Abstract: Evaluating Industry 4.0 technology application in small and medium-sized enterprises (SMEs) is an issue that requires a multi-criteria strategy comprising quantitative and qualitative elements. The purpose of this study is to integrate performance estimation of Industry 4.0 technology application using the technology-organization-environment (TOE) framework. Relating TOE to Industry 4.0 technology application evaluation is more multifaceted than other methods and it requires comprehensive analysis. In this study, we applied a multiple-criteria decision-making (MCDM) approach to develop a model which integrates MCDM to perform an assessment that prioritizes the influence weights of Industry 4.0 technology application to SMEs' factors. Firstly, we carried out a review of the literature and the TOE framework was selected to generate nine elements, along with three aspects used to measure Industry 4.0 technology application in SMEs. Secondly, the approach of the decision-making trial and evaluation laboratory (DEMATEL) was set up using an influence network relations digraph (INRD). The DEMATEL-based analytic network process (DANP) was used to indicate the influence weights linking the above aspects and elements. Lastly, the modified VlseKriterijumska Optimizacija I Kompromisno Resenje (VIKOR) technique applied influence weights to assess the aspects/elements in the gaps identified and to investigate how to reduce the gaps so as to estimate the application of Industry 4.0 technology by SMEs. The results show that the technology aspect is the most influential factor.

Keywords: industry 4.0 technology; small and medium-sized enterprises (SMEs); technologyorganization-environment (TOE); multiple-criteria decision-making (MCDM)

\section{Introduction}

Owing to the advancement of science and technology, numerous fields are gradually moving toward automation and intellectualization. The technology of Industry 4.0 represents the convergence of a range of emerging and novel technologies, such as cloud computing, smart sensors, big data, additive manufacturing (AM), robotics, artificial intelligence (AI), machine learning (ML), Internet of Things (IoT), and augmented reality [1-7]. These progressive technologies' participation in Industry 4.0 is reorganizing entire operational structures via centralized workflows and transforming analog to decentralized and digital manufacturing procedures [8-12]. The technologies have a high potential to importantly enhance the manufacturing productivity by converting regular manufacturing to automated production. Industry 4.0 has been beneficial to the production sector in three different ways: End-to-end engineering; vertical integration; and horizontal integration [13-16]. It combines data, machines, and people, thereby establishing more responsive and agile supply chains.

Industry 4.0 is incorporated into smart manufacturing and advanced manufacturingfor example, as an implementable structure where agile lines automatically adjust manufacturing procedures for multiple varying factors and products $[17,18]$. Industry 4.0 technologies enhance the flexibility, productivity, and quality and are able to assist with 
the execution of a broad scope of customized production and sustainable procedures with less resource consumption [18,19].

Existing studies have recorded different definitions of the Industry 4.0 technology model. Some of these studies have examined the sub-domains and contributions of Industry 4.0 technology, including the growth, organization, environment, and technology tendencies of the sub-domains of Industry 4.0 technology [20-23]. Nevertheless, some of these studies have only presented the Industry 4.0 technology application model, and did not evaluate the application of Industry 4.0 technology to strategic models through a systematic and process viewpoint. They also did not determine the influence relations and application models or main strategy of Industry 4.0 technology. Therefore, in this research, we propose a structured perspective for the evaluation of Industry 4.0 technology's application in small and medium-sized enterprises (SMEs).

While IT application in SMEs relates to the combination of the technology-organizationenvironment (TOE) structure and moves to IT innovation enhancement, managers must improve its application to enhance procedures, practices, designs, and services when they adopt Industry 4.0 technology $[19,24]$. Owing to the lack of previous studies about the parameters for assessing Industry 4.0 technology application, this study investigates the Industry 4.0 technology application in SMEs to establish the potential for performance progress. The purpose of this research is to propose a fit approach for estimating Industry 4.0 technology's potential to improve the performance in SMEs. Therefore, the paper has two contributions: It develops a theoretical basis linking Industry 4.0 technology application to the business performance in SMEs, and it estimates the influence of Industry 4.0 technology application on diverse aspects of the business performance. In light of hypercompetitive, commerce performance enhancement, SMEs need to formulate and apply schemes that protect their competitive advantage and improve their performances. As the most important sectors in Taiwan, it is especially necessary to notice the improvement of SMEs.

This study examines the effect of aspects of technology (technology readiness, technology security, and technology integration), organization (financial commitment, organization readiness, and top management support), and environmental criteria (regulatory support, competitive pressure, and environmental uncertainty) on Industry 4.0 technology application. The study's model and assumed relations are tested via data collected from top managers and related studies of SMEs in Taiwan. This study's findings contribute to empirical studies on the elements that impact Industry 4.0 technology application decisions. Importantly, this study applies group opinions of experts' practical experience, rather than a few isolated cases. Given the significance of Industry 4.0 technology application in the present and future, this study's findings will help administrators in targeting suitable decision-making models to effectively support Industry 4.0 technology application.

Industry 4.0 technology application strategies are independent and dependent, changing according to specialists' opinions and experience. Some general multiple criteria decision-making (MCDM) prototypes cannot categorize complicated networks in relation to different hierarchical structures of factors in contexts such as SMEs [25]. Furthermore, MCDM models usually employ the average judgement of specialists regarding decisionmaking procedures [25-28]. Lately, numerous methods have been presented to deal with the performance of Industry 4.0 technology application, such as the analytical network process (ANP) and the analytic hierarchy process (AHP) $[29,30]$. Nevertheless, these evaluation methods have numerous limitations. First, based on their approaches of only a single element, they are unable to integrate numerous performance elements. Additionally, they are lacking in terms of perceiving the influence weights of sub-elements and main elements and, thus, impartiality when estimating the performance. Therefore, this paper offers an integrated MCDM model which addresses the various problems within aspects of Industry 4.0 technology application and meets administrators' goals.

Most conservative multi-attribute decision analysis approaches cannot deal with the investigation of multifaceted interrelations between dissimilar hierarchical factors $[27,28]$. 
Adoption of the application of Industry 4.0 technology involves a decision approach structure that does just that. We can realize this research objective by applying the following methods: We can first build a mixed MCDM approach which integrates the decisionmaking trial and evaluation laboratory (DEMATEL) to establish an influence network relations digraph (INRD), known as the DEMATEL-based ANP (DANP), to indicate the influence weights of elements and the weights of the modified VlseKriterijumska Optimizacija I Kompromisno Resenje (VIKOR) technique by applying the DANP's influence weights to estimate and combine the gaps in performance. After that, we can study how to reduce these gaps through enhancement to enable the application of Industry 4.0 technology according to the INRD. These mixed techniques overcome the limits of existing evaluation approaches and can be applied to help us investigate the factors that impact the application of Industry 4.0 technology in real life. In this research, we used SMEs in Taiwan as a case study with which to consider the interdependence among factors that impact Industry 4.0 technology application, as well as assess alternative financial and business performances to reduce these gaps in performance among individual aspects in the bid to apply Industry 4.0 technology using an INRD in SMEs.

The study is organized as follows. We review the factors influencing technology, organization, and environmental aspects in the Industry 4.0 technology application model in Section 2. This section draws on the literature to build assessment elements. Section 3 describes the detailed methodology, including the hybrid MCDM method. Next, Section 4 introduces the case study. Lastly, Section 5 presents the study's conclusions.

\section{Literature Review}

The objective of this section is to study papers related to the Industry 4.0 technology application procedure, to associate and explore numerous assessment contexts, and to classify possible elements that impact the application procedure of Industry 4.0 technology in SMEs. Owing to the shortage of prior studies on the factors applied in assessing Industry 4.0 technology application [31,32], this paper develops an assessment structure applied in other firms and industries, including three primary aspects-technology, organization, and environment-with the goal of recognizing the factors which are most relevant for the application of Industry 4.0 technology.

\subsection{Related Literature on the Elements Influencing Industry 4.0 Technology Application in SMEs}

Industry 4.0 technology is one of the most promising technologies with the tendency to enhance process effectiveness and increase supply chain visibility $[15,16]$. Rapid changes in demand and intensified competition in the market have pushed manufacturing industries to implement innovative technology to enhance smart manufacturing. Industry 4.0 is the present data exchange and automation trend in technology of production $[33,34]$. During the last ten years, future industrial developments have been regularly discussed within academia and industry, whereas numerous viewpoints have emerged to define such developments. The successful growth of such development is considered vital to establishing competitive advantages between national economies and manufacturing firms [35,36]. The most established is Industry 4.0 within Europe [37-40]. Industry 4.0 emerged in Germany and was intended to sustain national growth via promoting the development of manufacturing in 2011. [41]. There are a variety of other initiatives that can be employed to enhance the development, for example, "Future of Manufacturing" in the UK and "Smart Manufacturing" in the USA [13,36].

While Industry 4.0 is well-expected, a major study solving the implementation approaches has been established via multi-national enterprises or larger organizations [42]. Although multi-national enterprises promote the economy in an important way [43], it cannot be neglected that SMEs make up 90\% of enterprises operating within the EU [44]. The influence of SMEs is also essential; they ensure social stability, create jobs, and promote economic growth [45,46]. Compared with multi-national enterprises, SMEs tend to face greater knowledge and financial resource constraints $[47,48]$. This has led to numerous 
researchers identifying a mismatch among present Industry 4.0 theory and the particular demands of SMEs [48-51]. Related research is changing in the wake of Industry 4.0 developments in terms of execution, planning, and associated investigation groups [52]. These responses to Industry 4.0 are full of numerous challenges in SMEs, particularly with regards to logistics, technologies, and managerial and organizational perspectives [53]. Fettermann et al. [54] inspected the demands of dissimilar technology, for example, cyber-physical systems, processing in cloud and radio frequency identifiers. Hofmann and Rüsch [55] stated the chances of Industry 4.0 in the logistics context. They stated that management is facing challenges in the adoption of Industry 4.0 because corporations may not detect any short-term financial performance after the adoption of Industry 4.0. In the management context, Barreto et al. [56] investigated the necessities that may enable companies to be more effective at adopting Industry 4.0. Oesterreich and Teuteberg [57] studied the challenges which Industry 4.0 poses for the industry of construction. Ben-Daya et al. [58] expanded the Industry 4.0 conception via the supply chain. Haddud et al. [59] investigated potential challenges and benefits related to the combination of Industry 4.0 from managerial and organizational perspectives.

The challenges associated with Industry 4.0 cause an unbalanced distribution of resources, which is important to and impactive in numerous other sectors of business [60-64]. Without a sufficient comprehension of the concerning Industry 4.0 elements, it is unlikely to exactly apply a suitable approach in response to this tendency [65-68]. Therefore, numerous industries are using Industry 4.0 technology for investigational developments to gain competitive advantages and enhance the operational efficiency through the viewpoint of technology, organization, environment and related business factors [20-23]. Industry 4.0 technology has also been receiving significant consideration in SMEs as it deals with the critical problems of automation and production efficiency in manufacturing operations, as indicated when inspecting the approaches in this study [69-71]. Industry 4.0 technology applications can be divided into several major performances (such as the finance performance, business performance, supply chain management performance, and so on), according to various SME objectives. Nevertheless, we only apply two alternatives ("finance performance $\left(A_{1}\right)$ " and "business performance $\left(A_{2}\right)$ ") in our approach as instances to indicate two comparatively good uses for Industry 4.0 technology applications.

The TOE structure illustrates how these contexts influence the implementation and adoption of innovation through three dissimilar factors [20-23,72]. The technology aspect focuses on the technology features that influence corporation implementation, the organization aspect focuses on implementation to the organization's attributes, and the environment aspect reflects the environmental factors [20,21]. Researchers have used the TOE structure to explore the implementation of numerous technologies, such as e-commerce, $3 \mathrm{D}$ printing, radio frequency identification (RFID) adoption, and so on $[25,73,74]$. For example, Lu et al. [74] explored and identified RFID adoption according to the TOE structure and the study demonstrated that RFID adoption had an important influence on each related performance. In addition, Lu et al. [25] extended this generalizability of previous research on business to business implementation to keeping usage. They did this from the perspective of network reliability, data security, top management emphasis, technology complexity, firm size, employees' information system (IS) knowledge, regulatory support, partner support, and competitive pressure. Mostly, the advantage of the TOE structure is its formidable background of theory and possible empirical adoption, which is beneficial in guiding scholars.

Previous researchers on Industry 4.0 technology application have seldom focused on all TOE aspects. Numerous researchers have restricted their argument to only a limited critical element and there is no systemic evaluation strategy in their studies. Therefore, in this study, these elements in each aspect are determined from a review of the related literature and numerous face-to-face interviews with these specialists in SMEs or related industry. Table 1 reviews references for all elements in the research. We state this TOE context as a base, resulting in the three aspects of our study's context-TOE (technology, organization, 
and environment). The factors related to the Industry 4.0 technology application within each aspect are subsequently discussed.

Table 1. Clarification of elements and aspects.

\begin{tabular}{|c|c|}
\hline Aspects/Element & Descriptions \\
\hline \multicolumn{2}{|l|}{ Technology aspect (G1) } \\
\hline Technology readiness $(g 1)$ & $\begin{array}{l}\text { Technology needs to be organized to make procedure changes, and latent sites } \\
\text { must make changes for Industry } 4.0 \text { technology if benefits are to accrue. }\end{array}$ \\
\hline Technology security $(g 2)$ & $\begin{array}{l}\text { This refers to internet platforms being considered secure for conducting online } \\
\text { transactions and exchanging data, including isolated data security and } \\
\text { protection in using Industry } 4.0 \text { technology. }\end{array}$ \\
\hline Technology integration $(g 3)$ & $\begin{array}{l}\text { This refers to improving the responsiveness of information systems and } \\
\text { decreasing incompatibility between legacy systems. }\end{array}$ \\
\hline \multicolumn{2}{|l|}{ Organization aspect (G2) } \\
\hline Financial commitment $(g 4)$ & $\begin{array}{l}\text { This refers to the company that can offer the financial resources for FinTech, } \\
\text { and is especially committed to investing in employee training, software, } \\
\text { hardware, system development, and system integration. }\end{array}$ \\
\hline Organizational readiness $(g 5)$ & $\begin{array}{l}\text { This refers to potential sites having to make decisions and businesses needing } \\
\text { to be prepared to make business procedure changes for Industry } 4.0 \\
\text { technology if benefits are to accrue. }\end{array}$ \\
\hline Top management support $(g 6)$ & $\begin{array}{l}\text { This refers to the top managers offering the support, and a promise to ensure a } \\
\text { positive influence on this Industry } 4.0 \text { technology application procedure. }\end{array}$ \\
\hline \multicolumn{2}{|l|}{ Environment aspect (G3) } \\
\hline Competitive pressure $(g 7)$ & $\begin{array}{l}\text { This refers to the adoption of Industry } 4.0 \text { technology, so that companies can } \\
\text { benefit from more accurate data collection and a greater operational efficiency. }\end{array}$ \\
\hline Regulatory support (g8) & $\begin{array}{l}\text { This refers to elements of conception such as the policies of the government, } \\
\text { which impact the diffusion of IT. }\end{array}$ \\
\hline Environmental uncertainty $(g 9)$ & $\begin{array}{l}\text { This refers to the environmental uncertainty, and how managers and } \\
\text { entrepreneurs tend to act proactively according to well-informed conjectures } \\
\text { about the strategic path ahead. }\end{array}$ \\
\hline
\end{tabular}

\subsection{Elements for Assessing the Industry 4.0 Technology Application Procedure}

The factors employed for assessing Industry 4.0 technology application will now be presented.

Technology aspect $\left(G_{1}\right)$ : Technology elements are denoted as "innovation characteristics" in numerous studies on administrative application procedures [20,21,75]. Technology readiness, technology security, and technology integration have all been recommended as significant to Industry 4.0 technology applications and are applied in the assessment context [21,22].

Organization aspect $\left(G_{2}\right)$ : Organizational features are present when applying novel technologies, as illustrated by Masood and Egger [21], and these are pertinent to the procedure of application. Numerous studies have highly esteemed Industry 4.0 technology application, with factors such as financial commitment, organizational readiness, and top management support considered to have a latent influence [20-23].

Environment aspect $\left(G_{3}\right)$ : Masood and Egger [21] have stated the impact of the environment in a management's strategies to implement novel technology. Competitive pressure, regulatory support, and environmental uncertainty are considered as being the most significant external elements [20-23].

This assessment structure focuses on TOE as the three aspects which significantly influence Industry 4.0 technology application in SMEs. Within each aspect, there are 
also lower-level factors, considered in former research. Our entire assessment structure, involving both the aspects and elements, is demonstrated in Table 1.

\section{Methods}

The mixed MCDM model assembled by applying the above mentioned research is considered to be an appropriate method for the prospecting of topics concerning the industry 4.0 technology application in SMEs. It can be employed as a case for managers to enhance TOE estimation approaches for each element. This mixed MCDM with pattern systematic approaches is not only applied for ranking and choosing, but also for explaining the issues among dissimilar elements and the aspects for Industry 4.0 technology application. The tendency in the present method is to divert through ranking and selection to obtain improvement of the commerce performance according to the INRD [1,25-28,75,76].

This DEMATEL approach is used to set up a matrix of total influence relations and to survey this effect and cause inter relations among parameters extracted through distinct criteria and elements. Then, we integrate the influence relations matrix acquired by the DEMATEL approach to set up the fundamental ANP [77] and determine the influence weights for each element.

\subsection{DEMATEL Technique}

DEMATEL is applied to establish this matrix of effect relations for aspects/elements to calculate the effects and causes for separate factors. The method is broadly used in numerous kinds of multifaceted research to understand the complexity of certain topics. DEMATEL involves five phases.

This primary phase checks the numberer of factors in a structure, $n$, and advances the gages for determining the influence relations in separate factors, associating aspects/elements in pairs and applying the measure of $0-4$, which represents a total lack of effect (0), low effect (1), medium effect (2), high effect (3), and very high effect (4).

The next phase detects a matrix of primary influence, associating effect interplay degree pairs to directly acquire the effect matrix $A=\left[a_{i j}\right]_{n \times n^{\prime}}$, where $a_{i j}$ indicates the degree to which element $i$ influences element $j$. If these $i$-th elements directly affect the $j$-th element, then $a_{i j} \neq 0$; then, $a_{i j}=0$.

The next phase normalizes the matrix of the direct effect to acquire the matrix $\boldsymbol{Z}$ from Equations (1) and (2). The matrix $\boldsymbol{Z}$ for the diagonal is 0 , and the largest summation of each column or row is 1 .

$$
v=\min _{i, j}\left\{\frac{1}{\max _{i} \sum_{j=1}^{n}\left|a_{i j}\right|}, \frac{1}{\max _{j} \sum_{i=1}^{n}\left|a_{i j}\right|}\right\}, i, j=1,2, \ldots, n
$$

The fourth phase acquires the total effect matrix $G$ from Equation (3):

$$
\boldsymbol{G}=\mathbf{Z}+\mathbf{Z}^{2}+\cdots+\mathbf{Z}^{h}=\mathbf{Z}(\boldsymbol{F}-\mathbf{Z})^{-1}, \text { when } \lim _{h \rightarrow \infty} \mathbf{Z}^{h}=[0]_{n \times n^{\prime}}
$$

where $\boldsymbol{Z}=\left[z_{i j}\right]_{n \times n^{\prime}} 0 \leq z_{i j}<1,0<\sum_{j=1}^{n} z_{i j} \leq 1,0<\sum_{i=1}^{n} z_{i j} \leq 1$. If the column or row is equal to 1 for at least some total factors (but not all) in $\sum_{j=1}^{n} z_{i j}$ and $\sum_{i=1}^{n} z_{i j}$, then we are able to determine that $\boldsymbol{F}$ is the identity matrix and $\lim _{h \rightarrow \infty} Z^{h}=[0]_{n \times n}$.

The final phase acquires the relations and prominence of these variables. Through all individual columns and rows of the total effect matrix $G=\left[g_{i j}\right]$, we can acquire the summation of all column and row vectors as follows:

$$
\boldsymbol{e}=\left[e_{i}\right]_{n \times 1}=\left[\sum_{j=1}^{n} g_{i j}\right]_{n \times 1}=\left(e_{1}, \ldots, e_{i}, \ldots, e_{n}\right)^{\prime},
$$




$$
\boldsymbol{o}=\left[o_{j}\right]_{1 \times n}^{\prime}=\left[\sum_{i=1}^{n} g_{i j}\right]^{\prime} 1 \times n=\left(o_{1}, \ldots, o_{j}, \ldots, o_{n}\right)^{\prime} .
$$

The value $e_{i}$, which is the summation of all rows in the total influence matrix $G$, denotes the degree to which this element indirectly or directly impacts other elements. The value $v_{j}$, which s the summation of all columns in $G$, indicates the degree that the element is influenced by other elements. Based on this explanation, $e_{i}+o_{j}$ indicates the degree of the total relations among the elements, meaning "prominence", whilst $e_{i}-o_{i}$ shows the degree of the impact and other elements, illustrating the "net influence relations". If $\left(e_{i}-o_{i}\right)$ is positive, then element $i$ influences the other elements, and if $\left(e_{i}-o_{i}\right)$ is negative, then element $i$ is affected by other elements.

\subsection{DANP Method}

DEMATEL is not only used to build the interplay relations between each element, but also to acquire the most exact weight of the impact. The traditional ANP resolves these issues through the feedback and interdependence of elements. Therefore, we apply these fundamental ANP conceptions [77] as a foundation and associate them with the DEMATEL to resolve these problems $[1,25,28,77,78]$. In this way, DANP covers the next phases.

The first phase builds the framework of the specialist influence survey. The survey is broken down and divided into components.

The next phase uses an unweighted supermatrix $B=\left(G_{c}^{\alpha}\right)^{\prime}$, transposing separate normalized characteristics with the total degree of influence $G_{c}^{\alpha}$ achieved by the matrix $G_{c}$ of the total effect by applying the DEMATEL, as illustrated in Equation (4).

$$
\begin{aligned}
& \begin{array}{ccccc}
E_{1} & & E_{j} & & E_{n} \\
c_{11} \ldots c_{1 m_{1}} & \ldots & c_{j 1} \ldots c_{j m_{j}} & \ldots & c_{n 1} \ldots c_{n m_{n}}
\end{array} \\
& \begin{array}{ll}
E_{1} & c_{11} \\
& c_{12}
\end{array} \\
& \text { : } \\
& \vdots \quad c_{1 m_{1}} \\
& \begin{array}{cc} 
& \\
& \\
& c=m_{1} \\
& c_{i 2} \\
& E_{i} \\
& \vdots \\
& c_{i m_{i}}
\end{array} \\
& \begin{array}{l}
\vdots \\
\quad \\
c_{n 1} \\
c_{n 2}
\end{array} \\
& \begin{array}{ll}
E_{n} & \vdots \\
c_{n m_{n}}
\end{array} \quad\left[\begin{array}{lllll}
G_{c}^{n 1} & \ldots & G_{c}^{n j} & \ldots & G_{c}^{n n}
\end{array}\right]
\end{aligned}
$$


The normalized $G_{c}$ with a total degree of effect offers the $G_{c}^{\alpha}$ of the aspects illustrated in Equation (5).

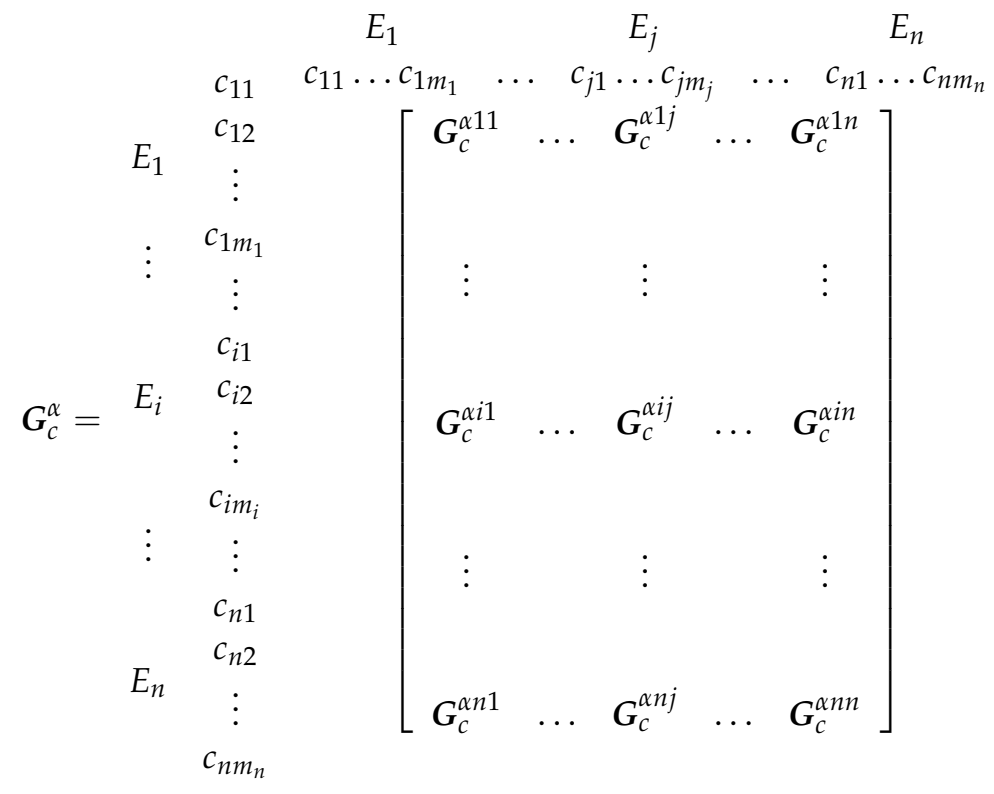

We use $G_{c}^{\alpha 11}$ to indicate the fundamental conception in Equations (6) and (7).

$$
e_{i}^{11}=\sum_{j=1}^{m_{1}} g_{C^{i j}}^{11}, i=1,2, \ldots, m_{1}
$$

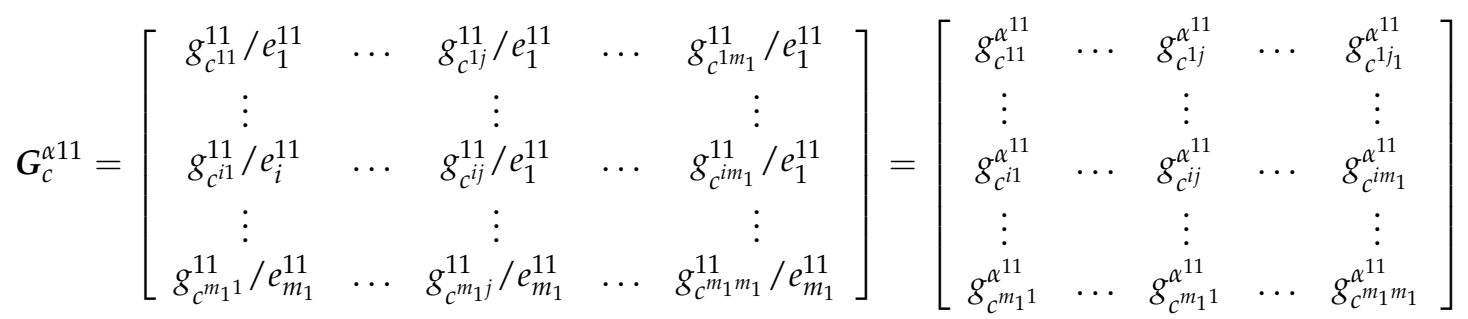

Then, it normalizes the matrix $G_{c}$ of the total influence into the matrix $G_{c}^{\alpha}$ applying its aspects; formerly, the unweighted supermatrix $B$ is attained via transposing $G_{c}^{\alpha}$, i.e., $\boldsymbol{B}=\left(\boldsymbol{G}_{c}^{\alpha}\right)^{\prime}$, according to the fundamental ANP conception in an unweighted supermatrix $\boldsymbol{B}$, as illustrated in Equation (8). 


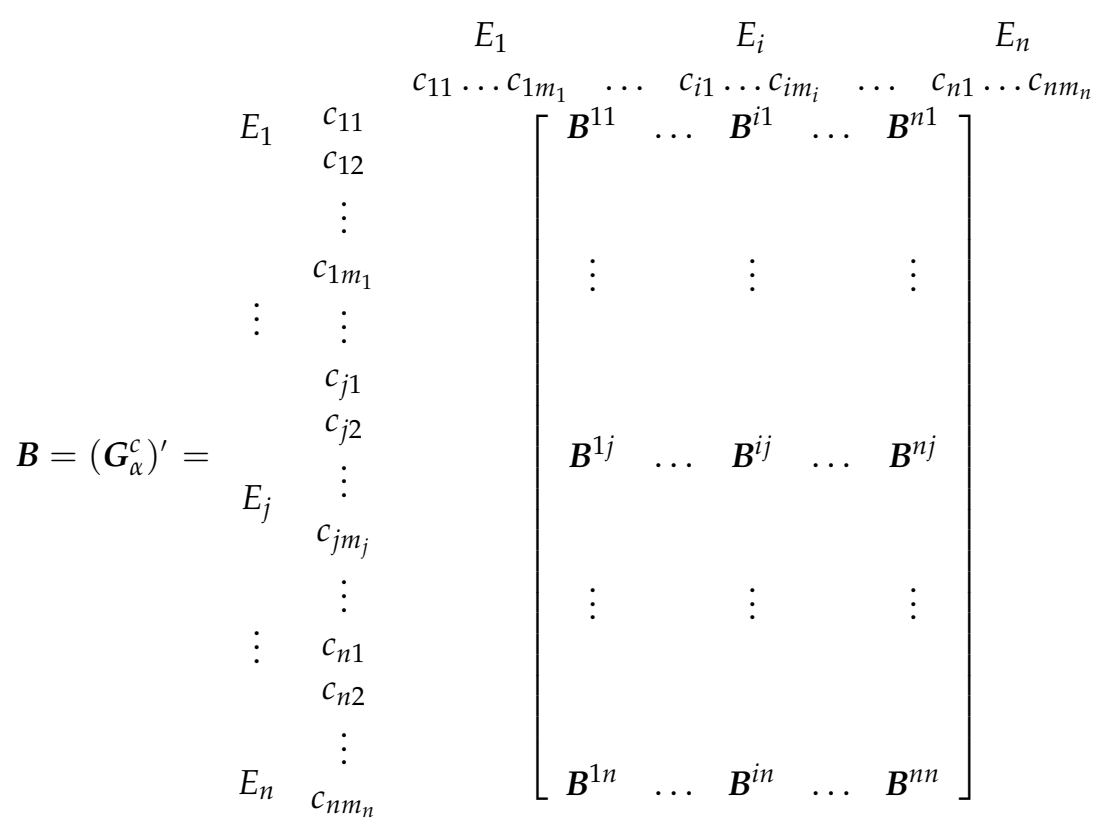

This produces matrix $\boldsymbol{B}^{11}$, as shown in Equation (9). If these clusters or elements are independent, the consistent item in this matrix is zero or blank. The matrix $\boldsymbol{B}^{n n}$ is attained in a similar way.

$$
\boldsymbol{B}^{11}=\left(\boldsymbol{G}^{11}\right)^{\prime}=\begin{gathered}
c_{11} \\
\vdots \\
c_{1 j} \\
\vdots \\
c_{1 m_{1}}
\end{gathered}\left[\begin{array}{ccccc}
g_{c^{11}}^{\alpha 11} & \cdots & g_{c i 1}^{\alpha 11} & \cdots & g_{c m_{1} 1}^{\alpha 11} \\
\vdots & & \vdots & & \vdots \\
g_{c^{1 j}}^{\alpha 11} & \cdots & g_{c i j}^{\alpha 11} & \cdots & g_{c}^{\alpha 11} \\
\vdots & & \vdots & & \vdots \\
g_{c^{1 m}}^{\alpha 11} & \cdots & g_{c i m}^{\alpha 11} & \cdots & g_{C}^{\alpha 11} \\
c_{1} m_{1} m_{1}
\end{array}\right]
$$

The third phase acquires the weight of the supermatrix, aspectualizing the matrix $G_{e}$ of the total influence relations matrix $G_{e}$ (as shown in Equation (10)). Agreement per aspect of matrix $G_{e}$ is normalized by the full effect to acquire $G_{E}^{\alpha}$. Equation (11) illustrates the outcome:

$$
\begin{aligned}
& e_{i}=\sum_{j=1}^{n} g_{E}^{i j}, i=1,2, \ldots, n \text { and } g_{E}^{\alpha i j}=g_{E}^{i j} / e_{i}, i=1,2, \ldots, n \\
& \mathbf{G}_{E}=\left[\begin{array}{ccccc}
g_{E}^{11} & \cdots & g_{E}^{1 j} & \cdots & g_{E}^{1 n} \\
\vdots & & \vdots & & \vdots \\
g_{E}^{i 1} & \cdots & g_{E}^{i j} & \cdots & g_{E}^{i n} \\
\vdots & & \vdots & & \vdots \\
g_{E}^{n 1} & \cdots & g_{E}^{n j} & \cdots & g_{E}^{n n}
\end{array}\right] \\
& G_{E}^{\alpha}=\left[\begin{array}{ccccc}
g_{11}^{E} / e_{1} & \ldots & g_{E}^{1 j} / e_{1} & \ldots & g_{E}^{1 n} / e_{1} \\
\cdots & & \ldots & & \cdots \\
g_{E}^{i 1} / e_{i} & \ldots & g_{D}^{i j} / e_{i} & \ldots & g_{E}^{i n} / e_{i} \\
\ldots & & \ldots & & \ldots \\
g_{E}^{n 1} / e_{n} & \ldots & g_{D}^{n j} / e_{n} & \ldots & g_{E}^{n n} / e_{n}
\end{array}\right]=\left[\begin{array}{ccccc}
e_{E}^{\alpha 11} & \ldots & e_{E}^{\alpha 1 j} & \ldots & e_{E}^{\alpha 1 n} \\
\ldots & & \ldots & & \ldots \\
e_{E}^{\alpha i 1} & \ldots & e_{E}^{\alpha i j} & \ldots & e_{E}^{\alpha i n} \\
\ldots & & \ldots & & \ldots \\
e_{E}^{\alpha n 1} & \ldots & e_{E}^{\alpha n j} & \ldots & e_{E}^{\alpha n n}
\end{array}\right] .
\end{aligned}
$$


Multiplying the normalized matrix $G_{E}^{\alpha}$ via the unweighted supermatrix $B$ offers the normalized supermatrix $\boldsymbol{B}^{\alpha}$, as illustrated in Equation (12).

$$
\boldsymbol{B}^{\alpha}=\boldsymbol{G}_{E}^{\alpha} \boldsymbol{B}=\left[\begin{array}{ccccc}
g_{E}^{\alpha 11} \times \boldsymbol{B}^{11} & \cdots & g_{D}^{\alpha i 1} \times \boldsymbol{B}^{i 1} & \cdots & g_{D}^{\alpha n 1} \times \boldsymbol{B}^{n 1} \\
\vdots & & \vdots & & \vdots \\
g_{E}^{\alpha 1 j} \times \boldsymbol{B}^{1 j} & \cdots & g_{D}^{\alpha i j} \times \boldsymbol{B}^{i j} & \cdots & g_{D}^{\alpha n j} \times \boldsymbol{B}^{n j} \\
\vdots & & \vdots & & \vdots \\
g_{E}^{\alpha 1 n} \times \boldsymbol{B}^{1 n} & \cdots & g_{D}^{\alpha i n} \times \boldsymbol{B}^{i n} & \cdots & g_{D}^{\alpha n n} \times \boldsymbol{B}^{n n}
\end{array}\right]
$$

The fourth phase acquires the normalized supermatrix $\boldsymbol{B}^{\alpha}$. The supermatrix limitation can be acquired by multiplying this supermatrix $\boldsymbol{B}^{\alpha}$ with normalization via itself numerous times, until the supermatrix has become and converged into a long-term stabilizing supermatrix to provide a big enough power $t$. Hence, these weights of the effect of individual elements are attained via $\lim _{t \rightarrow \infty}\left(\boldsymbol{W}^{\alpha}\right)^{t}$, where $t$ indicates any numeral for the exponent. We apply these procedures to acquire the influence weights.

\subsection{Modified VIKOR}

The VIKOR technique, established by Opricovic and Tzeng [78,79], resolves MCDM issues with inconsistent elements. The technique is associated with negative-ideal and positive-ideal resolutions, with a preference for being close to the point of positive-ideal, that is, the fundamental plan of accustomed thinking. The conception of gap procedures indicates the closeness to the point of positive-ideal $[78,79]$. We will now define this modified VIKOR technique.

The primary phase indicates the values $u_{j}^{*}$ and $u_{j}^{-}$in valuable element evaluation elements. The value $u_{j}^{*}$ denotes the positive-ideal point, that is, the best score for element $j$, and $u_{j}^{-}$denotes the point of the negative-ideal, representing the worst score for element $j$. $u_{p j}$ represents the score of the performance of the $p$ alternative for $j$. This evolution of the VIKOR technique starts with the following procedure of $Q_{p \_}$metric:

$$
Q_{p}^{k}=\left\{\sum_{j=1}^{n}\left[b_{j}\left(\left|u_{j}^{*}-u_{p j}\right|\right) /\left(\left|u_{j}^{*}-u_{j}^{-}\right|\right)\right]^{k}\right\}^{1 / k},
$$

where $1 \leq k \leq \infty ; p=1,2, \ldots, m$ and the influence of weight $w_{j}$ is derived through the DANP. In this study, we applied the conceptions of Equations (14) and (15) to acquire the next outcomes for enhancement of the gap of each aspect/element according to feedback and interdependence issues:

$$
u_{j}^{*}=\max _{p} x_{p j}, j=1,2, \ldots, n \text { (traditional approach) }
$$

We built the aspiration levels (modified approach) via the following vector:

$$
u^{*}=\left(u_{1}^{*}, u_{2}^{*}, \cdots, u_{n}^{*}\right)
$$

$u_{j}^{-}=\min _{p} u_{p j}, j=1,2, \ldots, n$ (traditional approach)

We built the worst values (modified approach) via the following vector:

$$
u^{-}=\left(u_{1}^{-}, u_{2}^{-}, \cdots, u_{n}^{-}\right) .
$$

The fundamental aspect of the modified method is that we apply the scores of the performance from 0 to 4 in surveys so that the aspired value can be established at 4 and the worst value at zero. Therefore, in this study, we established $u_{j}^{*}=10, j=1,2, \ldots, n$ as the aspired value and $j=1,2, \ldots, n, u_{j}^{-}=0$ as the worst level, representing a difference when compared to the traditional method. In the study, we established $u_{j}^{*}$ as the aspired value 
and $u_{j}^{-}$as the worst value, and were able to prevent selection of the best among lower alternatives.

The second phase analyses the minimal mean of the group utility $I_{p}$ and maximal regret $L_{p}$.

$$
\begin{gathered}
Q_{p}^{k=1}=I_{p}=\sum_{j=1}^{n} b_{j} r_{p j}=\sum_{j=1}^{n} b_{j}\left(\left|u_{j}^{*}-u_{k j}\right|\right) /\left(\left|u_{j}^{*}-u_{j}^{-}\right|\right), \\
Q_{p}^{k=\infty}=Q_{p}=\max _{j}\left\{r_{p j} \mid j=1,2, \ldots, n\right\},
\end{gathered}
$$

where $r_{p j}=\left(\left|u_{j}^{*}-u_{p j}\right|\right) /\left(\left|u_{j}^{*}-u_{j}^{-}\right|\right)$indicates the gap ratio; $I_{p}$ indicates the ratios of the average gap through the aspired level $u_{j}^{*}$ to the value of performance $u_{p j}$ in element $j$ of alternative $p$ in the study, and we focus on how to minimize this gap $r_{p j}$ for the element $j=1,2, \ldots, n$. Formerly, $b_{j}$ indicates the respective influence weight of element $j ; b_{j}$ can be obtained from the DANP according to the DEMATEL technique. $L_{p}$ indicates the maximum gap for all elements.

The last phase attains the overall factor $R_{p}$ and its sorted outcomes. Equation (17) computes the values. As shown in Equation (17), we can detect how to enhance the application of Industry 4.0 technology to decrease the gaps in reaching the desired value according to the influence network relation map.

$$
R_{p}=s\left(I_{p}-I^{*}\right) /\left(I^{-}-I^{*}\right)+(1-s)\left(L_{p}-L^{*}\right) /\left(P^{-}-P^{*}\right)
$$

The derived values are $I^{*}=0$ (as the gap is zero, achieving the desired level), $I^{-}=1$ (the worst situation)m $L^{*}=0$ (desired level), and $L^{-}=1$ (the worst situation). Therefore, in this study, we employed the gap for $V^{*}=0$ and $I^{-}=1, L^{*}=0$, and $L^{-}=1$, and modified Equation (17) as $R_{p}=s I_{p}+(1-s) L_{p}$. The weight $s=1$ only indicates how we are able to minimize this average gap, and the weight $s=0$ only indicates how to choose the maximum gap for previous enhancement. Generally, $s=0.5$, which can be regulated, depending on the circumstances.

According to the above conceptions, we could simply attain how to enhance these gaps $r_{k j}(p=1,2, \ldots, m ;)$, that is, the precedence for enhancement of the achieved aspired value.

\section{Case Analysis}

This empirical case focused on SMEs in Taiwan and is provided to show the application of the recommended MCDM pattern with the goal of choosing and evaluating the best approaches. The approach is able to help managers better handle matters of Industry 4.0 technology through the TOE structure and to realize their goals for distinct aspects/elements. A map of this study is shown in Figure 1. 


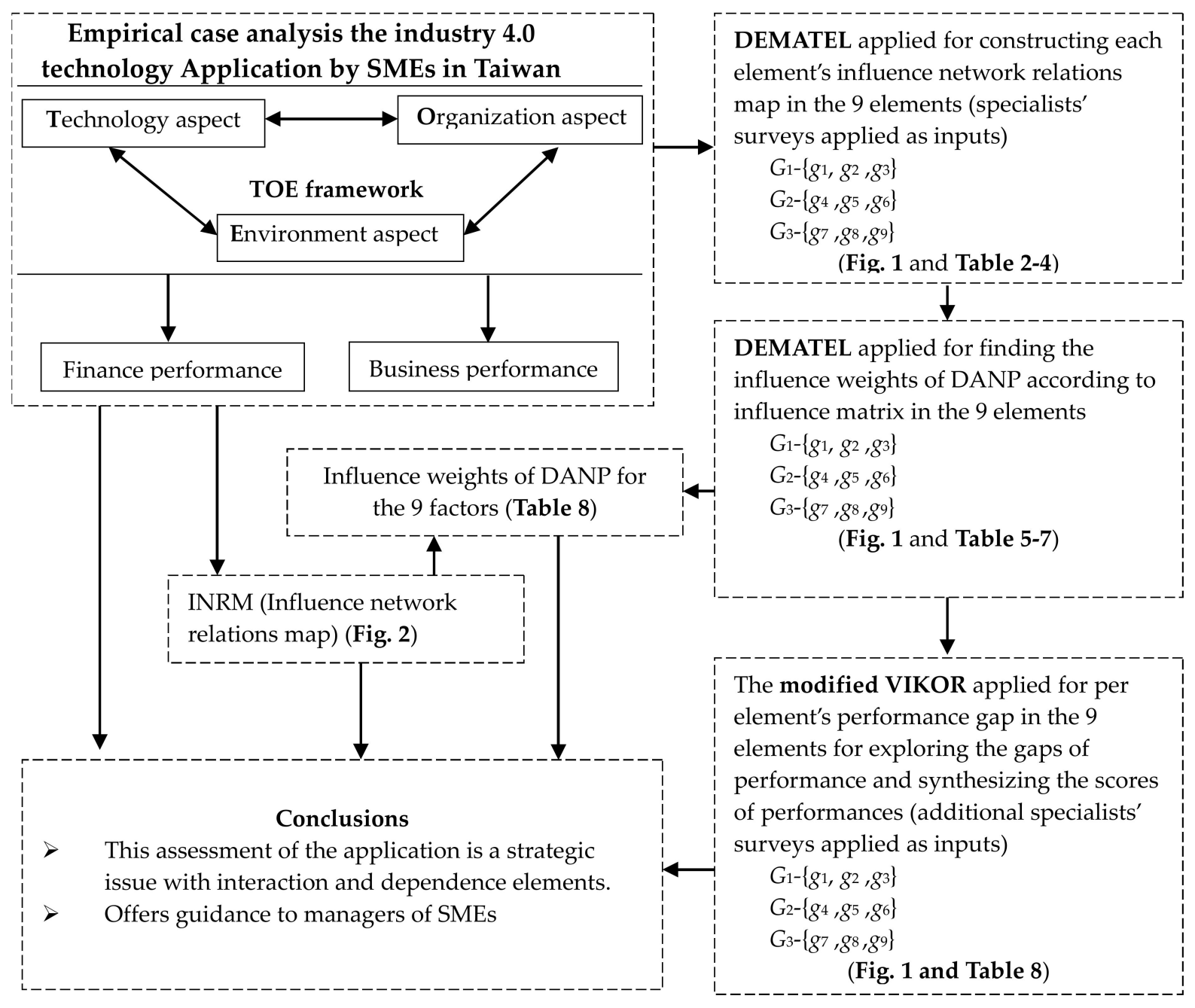

Figure 1. A map of the empirical case.

\subsection{Data Collection}

This study reviewed literature on Industry 4.0 technology and the application of information technology/information systems to SMEs, and relied on the context of TOE to choose Industry 4.0 technology application elements. The questionnaire was provided to specialists in the assessment of information technology application within associated fields. Firstly, the investigation applied a 5-point scale from 4 (very high effect) to 0 (completely no effect) to indicate the elements of impact of each aspect on the others. For these performance assessments, 12 specialists were questioned to assess their value of fulfillment for each element (see Table 2 in Note 1, where the gap error is $1.973 \%$; the significant confidence is $98.027 \%$, and it is more than 95\%). Most of these specialists had more than 12 years' experience as managers in SMEs. Professional viewpoints on all elements within the elements were gathered by a survey and individual interviews. The interviews with the specialists were carried out in December 2020, and they lasted for 25 to 30 min per session for the whole survey. 
Table 2. The total influence relationship matrix of $G_{C}$ for elements.

\begin{tabular}{llccccccccc}
\hline & Elements & $g_{1}$ & $g_{2}$ & $g_{3}$ & $g_{4}$ & $g_{5}$ & $g_{6}$ & $g_{7}$ & $g_{8}$ & $g_{9}$ \\
\hline$g_{1}$ & Technology readiness & 0.443 & 0.565 & 0.560 & 0.529 & 0.538 & 0.582 & 0.475 & 0.560 & 0.484 \\
$g_{2}$ & Technology security & 0.496 & 0.409 & 0.502 & 0.470 & 0.488 & 0.526 & 0.419 & 0.496 & 0.455 \\
$g_{3}$ & Technology integration & 0.458 & 0.458 & 0.357 & 0.385 & 0.441 & 0.449 & 0.376 & 0.432 & 0.388 \\
$g_{4}$ & Financial commitment & 0.488 & 0.510 & 0.495 & 0.386 & 0.500 & 0.533 & 0.461 & 0.483 & 0.432 \\
$g_{5}$ & Organizational readiness & 0.565 & 0.607 & 0.601 & 0.575 & 0.465 & 0.621 & 0.528 & 0.588 & 0.518 \\
$g_{6}$ & Top management support & 0.320 & 0.317 & 0.335 & 0.309 & 0.315 & 0.268 & 0.270 & 0.301 & 0.270 \\
$g_{7}$ & Competitive pressure & 0.548 & 0.570 & 0.554 & 0.537 & 0.526 & 0.570 & 0.395 & 0.578 & 0.501 \\
$g_{8}$ & Regulatory support & 0.475 & 0.466 & 0.461 & 0.451 & 0.451 & 0.470 & 0.425 & 0.375 & 0.385 \\
$g_{9}$ & Environmental uncertainty & 0.504 & 0.515 & 0.497 & 0.489 & 0.486 & 0.527 & 0.444 & 0.527 & 0.358 \\
\hline
\end{tabular}

Note 1: It is an $n \times n$ matrix and $n=9 . \frac{1}{n^{2}} \sum_{i=1}^{n} \sum_{j=1}^{n} \frac{\left|t_{i j}^{p}-t_{i j}^{p-1}\right|}{t_{i j}^{p}} \times 100 \%=1.973 \%<5 \%$, and significant confidence is $98.027 \%$, as $p=12$ represents the number of specialists and $t_{i j}^{p}$ is the average effect of the $i$ element on $j ; n$ represents the number of elements.

\subsection{Results Analysis}

In this research, we applied the strategic framework of DEMATEL and investigated it through nine (9) elements and three (3) aspects of the TOE context viewpoint on Industry 4.0 technology. By applying the expert surveys, we acquired the matrix $G$ of the total influence of aspects and elements illustrated in Tables 2 and 3 . We examined the opinions and thoughts of the specialists in terms of three (3) aspects, and the relations between the scopes of influence, which are compared to other aspects in Table 3.

Table 3. The summation of the effects on the aspects and total influence relations matrix of $G$.

\begin{tabular}{cccccccc}
\hline Aspects & $\boldsymbol{G}_{\mathbf{1}}$ & $\boldsymbol{G}_{\mathbf{2}}$ & $\boldsymbol{G}_{\mathbf{3}}$ & $\boldsymbol{e}_{\boldsymbol{i}}$ & $\boldsymbol{o}_{\boldsymbol{i}}$ & $\boldsymbol{e}_{\boldsymbol{i}}+\boldsymbol{o}_{\boldsymbol{i}}$ & $\boldsymbol{e}_{\boldsymbol{i}}-\boldsymbol{o}_{\boldsymbol{i}}$ \\
\hline Technology aspect & 0.472 & 0.490 & 0.454 & 1.415 & 1.453 & 2.868 & -0.037 \\
Organization aspect & 0.471 & 0.441 & 0.428 & 1.340 & 1.432 & 2.772 & -0.092 \\
Environment aspect & 0.510 & 0.501 & 0.443 & 1.454 & 1.325 & 2.779 & 0.129 \\
\hline
\end{tabular}

Based on the total influence prominence $\left(e_{i}+o_{j}\right)$, the "technology aspect $\left(G_{1}\right)$ " has the maximum influence of the relations detected; the "organization aspect $\left(G_{2}\right)$ " includes all of the aspects which influence the others at the most basic level. Based on the influence relations $\left(e_{i}-o_{i}\right)$, we can also observe that the "environment aspect $\left(G_{3}\right)$ " has the maximum level of impact in relation to other aspects calculated. Additionally, the "organization aspect $\left(G_{2}\right)^{\prime \prime}$ has the weakest influence in comparison to other aspects. Based on Table 4, we can acquire data on the relational influence among elements. Table 4 illustrates the direct and indirect relations among the aspects in relation to other elements. "Organizational readiness $\left(g_{5}\right)$ " is the most significant element considered; in addition, "top management support $\left(g_{6}\right)$ " influences all other elements at the most basic level. Moreover, Table 4 illustrates that "competitive pressure $\left(g_{7}\right)$ " has the maximum influence level in relation to the other elements. Moreover, "technology integration $\left(g_{3}\right)$ " has the weakest influence in relation to the other elements. 
Table 4. The sum of the effects on the elements.

\begin{tabular}{|c|c|c|c|c|c|}
\hline \multicolumn{2}{|c|}{ Aspects/Elements } & \multirow[t]{2}{*}{$e_{i}$} & \multirow[t]{2}{*}{$o_{i}$} & \multirow[t]{2}{*}{$e_{i}+o_{i}$} & \multirow[t]{2}{*}{$e_{i}-o_{i}$} \\
\hline$G_{1}$ & Technology aspect & & & & \\
\hline$g_{1}$ & Technology readiness & 4.736 & 4.298 & 9.033 & 0.438 \\
\hline$g_{2}$ & Technology security & 4.260 & 4.417 & 8.676 & -0.157 \\
\hline$g_{3}$ & Technology integration & 3.744 & 4.360 & 8.104 & -0.617 \\
\hline$G_{2}$ & Organization aspect & & & & \\
\hline$g_{4}$ & Financial commitment & 4.289 & 4.131 & 8.420 & 0.158 \\
\hline$g_{5}$ & Organizational readiness & 5.067 & 4.209 & 9.277 & 0.858 \\
\hline$g_{6}$ & Top management support & 2.706 & 4.546 & 7.252 & -1.841 \\
\hline$G_{3}$ & Environment aspect & & & & \\
\hline$g_{7}$ & Competitive pressure & 4.780 & 3.794 & 8.573 & 0.986 \\
\hline$g_{8}$ & Regulatory support & 3.959 & 4.340 & 8.299 & -0.382 \\
\hline$g_{9}$ & Environmental uncertainty & 4.347 & 3.791 & 8.138 & 0.556 \\
\hline
\end{tabular}

Previously, we applied DEMATEL to approve the relational influence for the elements, and we aimed to obtain the most precise influenced weights. DANP was used to resolve the interdependence and feedback issues of separate elements [25-28]. Therefore, we assembled the quality estimation model via DEMATEL, combined with DANP to acquire the weights of influence for the individual elements, as indicated in Tables 5-7.

Table 5. The unweighted supermatrix $\boldsymbol{B}=\left(\boldsymbol{G}_{c}^{\alpha}\right)^{\prime}$.

\begin{tabular}{lcccccccccc}
\hline & Elements & $g_{1}$ & $g_{2}$ & $g_{3}$ & $g_{4}$ & $g_{5}$ & $g_{6}$ & $g_{7}$ & $g_{8}$ & $g_{9}$ \\
\hline$g_{1}$ & Technology readiness & 0.283 & 0.360 & 0.357 & 0.321 & 0.326 & 0.353 & 0.313 & 0.369 & 0.319 \\
$g_{2}$ & Technology security & 0.352 & 0.291 & 0.357 & 0.317 & 0.329 & 0.354 & 0.306 & 0.362 & 0.332 \\
$g_{3}$ & Technology integration & 0.360 & 0.360 & 0.280 & 0.302 & 0.346 & 0.352 & 0.314 & 0.362 & 0.324 \\
$g_{4}$ & Financial commitment & 0.327 & 0.341 & 0.332 & 0.272 & 0.352 & 0.375 & 0.335 & 0.351 & 0.314 \\
$g_{5}$ & Organizational readiness & 0.319 & 0.342 & 0.339 & 0.346 & 0.280 & 0.374 & 0.323 & 0.360 & 0.317 \\
$g_{6}$ & Top management support & 0.329 & 0.326 & 0.344 & 0.346 & 0.353 & 0.300 & 0.321 & 0.358 & 0.321 \\
$g_{7}$ & Competitive pressure & 0.328 & 0.341 & 0.331 & 0.329 & 0.322 & 0.349 & 0.268 & 0.392 & 0.340 \\
$g_{8}$ & Regulatory support & 0.339 & 0.332 & 0.329 & 0.329 & 0.329 & 0.343 & 0.359 & 0.316 & 0.325 \\
$g_{9}$ & Environmental uncertainty & 0.333 & 0.340 & 0.328 & 0.325 & 0.324 & 0.351 & 0.334 & 0.397 & 0.269 \\
\hline
\end{tabular}

Table 6. The normalized supermatrix $B^{\alpha}=G_{D}^{\alpha} B$.

\begin{tabular}{lcccccccccc}
\hline & Elements & $g_{1}$ & $g_{2}$ & $g_{3}$ & $g_{4}$ & $g_{5}$ & $g_{6}$ & $g_{7}$ & $g_{8}$ & $g_{9}$ \\
\hline$g_{1}$ & Technology readiness & 0.094 & 0.118 & 0.120 & 0.115 & 0.112 & 0.116 & 0.115 & 0.119 & 0.117 \\
$g_{2}$ & Technology security & 0.120 & 0.097 & 0.120 & 0.120 & 0.120 & 0.115 & 0.119 & 0.117 & 0.119 \\
$g_{3}$ & Technology integration & 0.119 & 0.119 & 0.094 & 0.117 & 0.119 & 0.121 & 0.116 & 0.115 & 0.115 \\
$g_{4}$ & Financial commitment & 0.111 & 0.110 & 0.104 & 0.090 & 0.114 & 0.114 & 0.113 & 0.113 & 0.112 \\
$g_{5}$ & Organizational readiness & 0.113 & 0.114 & 0.120 & 0.116 & 0.092 & 0.116 & 0.111 & 0.113 & 0.111 \\
$g_{6}$ & Top management support & 0.122 & 0.123 & 0.122 & 0.124 & 0.123 & 0.099 & 0.120 & 0.118 & 0.121 \\
$g_{7}$ & Competitive pressure & 0.100 & 0.098 & 0.101 & 0.107 & 0.103 & 0.102 & 0.082 & 0.109 & 0.102 \\
$g_{8}$ & Regulatory support & 0.118 & 0.116 & 0.116 & 0.112 & 0.115 & 0.114 & 0.120 & 0.096 & 0.121 \\
$g_{9}$ & Environmental uncertainty & 0.102 & 0.106 & 0.104 & 0.100 & 0.101 & 0.102 & 0.104 & 0.099 & 0.082 \\
\hline
\end{tabular}


Table 7. The stable matrix of the decision-making trial and evaluation laboratory-based analytic network process (DANP) with the power limit of $\varphi \rightarrow \infty$, i.e., $\lim _{\varphi \rightarrow \infty}\left(B^{\alpha}\right)^{\varphi}$.

\begin{tabular}{lcccccccccc}
\hline & Elements & $g_{1}$ & $g_{2}$ & $g_{3}$ & $g_{4}$ & $g_{5}$ & $g_{6}$ & $g_{7}$ & $g_{8}$ & $g_{9}$ \\
\hline$g_{1}$ & Technology readiness & 0.114 & 0.114 & 0.114 & 0.114 & 0.114 & 0.114 & 0.114 & 0.114 & 0.114 \\
$g_{2}$ & Technology security & 0.116 & 0.116 & 0.116 & 0.116 & 0.116 & 0.116 & 0.116 & 0.116 & 0.116 \\
$g_{3}$ & Technology integration & 0.115 & 0.115 & 0.115 & 0.115 & 0.115 & 0.115 & 0.115 & 0.115 & 0.115 \\
$g_{4}$ & Financial commitment & 0.109 & 0.109 & 0.109 & 0.109 & 0.109 & 0.109 & 0.109 & 0.109 & 0.109 \\
$g_{5}$ & Organizational readiness & 0.112 & 0.112 & 0.112 & 0.112 & 0.112 & 0.112 & 0.112 & 0.112 & 0.112 \\
$g_{6}$ & Top management support & 0.119 & 0.119 & 0.119 & 0.119 & 0.119 & 0.119 & 0.119 & 0.119 & 0.119 \\
$g_{7}$ & Competitive pressure & 0.101 & 0.101 & 0.101 & 0.101 & 0.101 & 0.101 & 0.101 & 0.101 & 0.101 \\
$g_{8}$ & Regulatory support & 0.114 & 0.114 & 0.114 & 0.114 & 0.114 & 0.114 & 0.114 & 0.114 & 0.114 \\
$g_{9}$ & Environmental uncertainty & 0.100 & 0.100 & 0.100 & 0.100 & 0.100 & 0.100 & 0.100 & 0.100 & 0.100 \\
\hline
\end{tabular}

We defined the key elements in the application of Industry 4.0 technology to SMEs as top management support $\left(g_{6}\right)$, technology security $\left(g_{2}\right)$, and technology integration $\left(g_{3}\right)$. DEMATEL was integrated with the influence weights to estimate the precedence of resolving issues, according to the gaps determined through the modified VIKOR and the influence network relations map.

In this research, a case study relating the Industry 4.0 technology application to SMEs was used to estimate and enhance approval gaps by applying the modified VIKOR technique, as shown in Table 8. Managers can detect problems through the values of gaps, either from the viewpoint of the element or separate aspects.

Table 8. A gap evaluation of the application of Industry 4.0 technology by modified VlseKriterijumska Optimizacija I Kompromisno Resenje (VIKOR).

\begin{tabular}{|c|c|c|c|c|c|}
\hline \multirow{2}{*}{\multicolumn{2}{|c|}{ Aspects/Elements }} & \multirow{3}{*}{$\begin{array}{c}\text { Local Weights } \\
0.345\end{array}$} & \multirow{3}{*}{ Global Weights } & \multicolumn{2}{|c|}{ Industry 4.0 Technology Gap } \\
\hline & & & & \multirow{2}{*}{$\begin{array}{c}\text { FP } \\
0.428\end{array}$} & \multirow{2}{*}{$\begin{array}{c}\text { BP } \\
0.254\end{array}$} \\
\hline$G_{1}$ & Technology aspect & & & & \\
\hline$g_{1}$ & Technology readiness & 0.330 & 0.114 & 0.280 & 0.140 \\
\hline$g_{2}$ & Technology security & 0.337 & $0.116(2)$ & 0.560 & 0.360 \\
\hline $\begin{array}{l}02 \\
g_{3}\end{array}$ & Technology integration & 0.333 & $0.115(3)$ & 0.440 & 0.260 \\
\hline$G_{2}$ & Organization aspect & 0.340 & & 0.317 & 0.392 \\
\hline$g_{4}$ & Financial commitment & 0.321 & 0.109 & 0.427 & 0.240 \\
\hline$g_{5}$ & Organizational readiness & 0.329 & 0.112 & 0.420 & 0.320 \\
\hline$g_{6}$ & Top management support & 0.350 & $0.119(1)$ & 0.120 & 0.600 \\
\hline$G_{3}$ & Environment aspect & 0.315 & & 0.360 & 0.295 \\
\hline$g_{7}$ & Competitive pressure & 0.320 & 0.101 & 0.387 & 0.300 \\
\hline$g_{8}$ & Regulatory support & 0.362 & 0.114 & 0.320 & 0.320 \\
\hline$g_{9}$ & $\begin{array}{c}\text { Environmental } \\
\text { uncertainty }\end{array}$ & 0.318 & 0.100 & 0.380 & 0.260 \\
\hline \multicolumn{2}{|r|}{$S A_{1}$} & \multicolumn{2}{|c|}{ Total gaps } & 0.258 & 0.228 \\
\hline
\end{tabular}

By applying these elements and aspects, the performances of the gap can be indicated by the enhancement of precedence arrangements to achieve the desired values. In the application of Industry 4.0 technology, technology security $\left(g_{2}\right)$, with a high gap value of 0.560 , is the primary element to be enhanced for the financial performance; top management support $\left(g_{6}\right)$, with a high gap value of 0.600 , is the primary element to be enhanced for the business performance. The enhancement precedence is also able to be used in separate aspects for the financial performance and business performance. In terms of the financial performance, for the technology aspect $\left(G_{1}\right)$, for example, the precedence gap values are ordered as follows: Technology security $\left(g_{2}\right)$, technology integration $\left(g_{3}\right)$, and technology readiness $\left(g_{1}\right)$. For the organization aspect $\left(G_{2}\right)$, the precedence values of the gap are ordered as follows: Financial commitment $\left(g_{4}\right)$, organizational readiness $\left(g_{5}\right)$, and management support $\left(g_{6}\right)$. For the environment aspect $\left(G_{2}\right)$, the enhancement 
precedencies are ordered as follows: Competitive pressure $\left(g_{7}\right)$, environmental uncertainty $\left(g_{9}\right)$, and regulatory support $\left(g_{8}\right)$. For the business performance, in terms of the technology aspect $\left(G_{1}\right)$, improvement priorities are ordered as follows: $\left(g_{2}\right),\left(g_{3}\right)$, and $\left(g_{1}\right)$. The order is $\left(g_{6}\right),\left(g_{5}\right)$, and $\left(g_{4}\right)$ within the organization aspect $\left(G_{2}\right)$ and $\left(g_{8}\right),\left(g_{7}\right)$, and $\left(g_{9}\right)$ for the environment aspect $\left(G_{3}\right)$. When applying the gap values offered by the specialists, the comprehensive priority systems of enhancement for the disparate aspects and for the general array of elements are obvious, as illustrated in Table 8. For managers, realizing the enhancement precedence of the application of Industry 4.0 technology for clients' needs to be simpler to realize than these performance gaps in the SMEs.

\subsection{Implications and Discussion}

The outcomes of this paper will now be discussed. Initially, based on the DEMATEL, we can identify the interrelationship among separate elements and aspects from the influence relations network map for each element and aspect. In Figure 2, the "environment aspect $\left(G_{3}\right)$ " impacts other aspects, specifically, the "technology aspect $\left(G_{1}\right)$ " and "organization aspect $\left(G_{2}\right)^{\prime \prime}$; visibly, the environment aspect $\left(G_{3}\right)$ is a significant feature, and it has maximum strength impact in relation to other aspects. Therefore, the managers of SMEs need to prioritize enhancing this aspect. This is to be followed by the technology aspect $\left(G_{1}\right)$ and the organization aspect $\left(G_{2}\right)$ in assessing and enhancing the application of Industry 4.0 technology via SMEs.

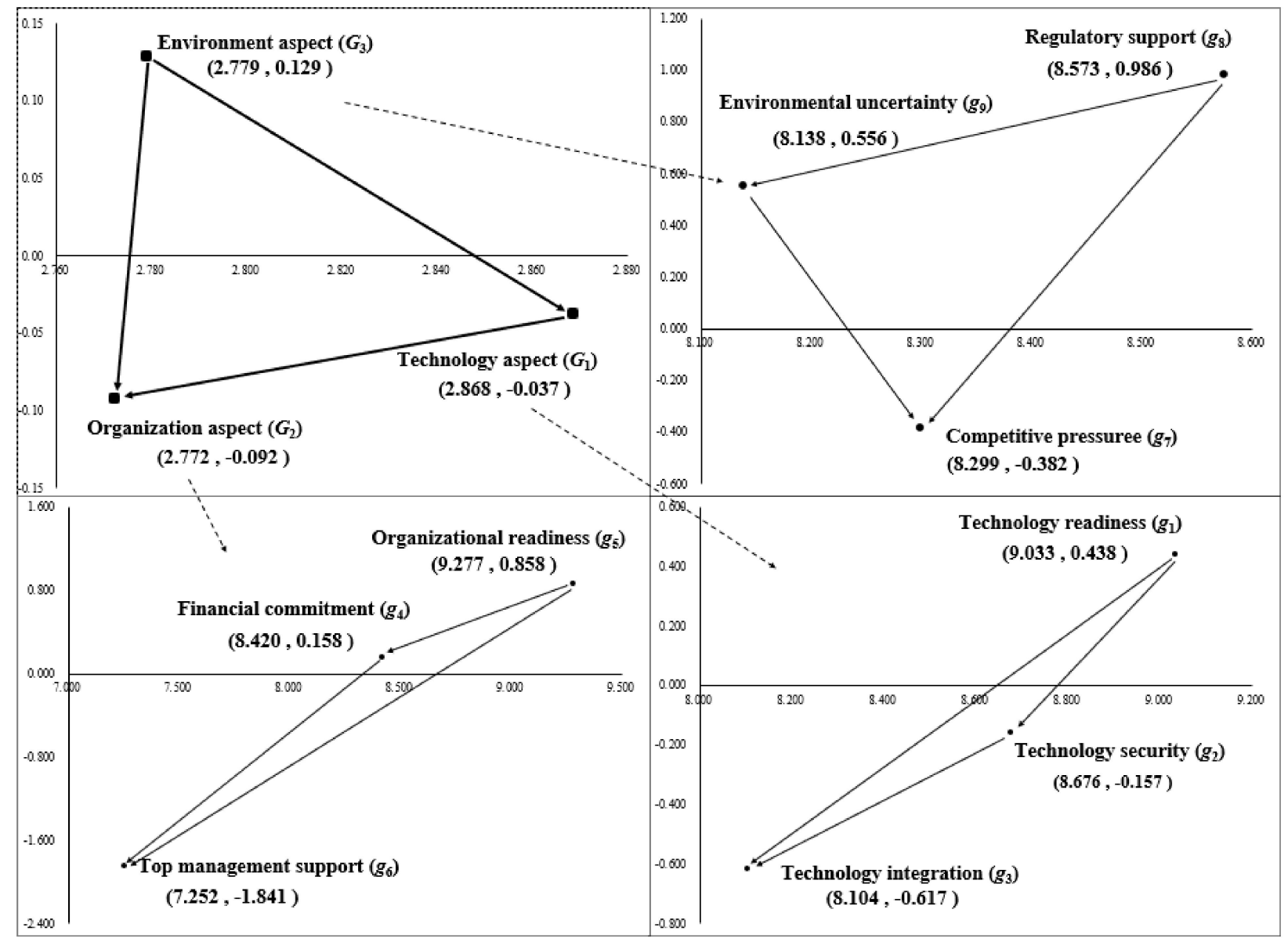

Figure 2. The influence network relations digraph (INRD) of each aspect and element.

Next, after inspecting these aspects, we focused on the elements, considered per aspect. Based on the findings, we developed a map of the influence relations of the elements in Figure 2. Therefore, for the effect relations among the elements, technology readiness 
$\left(g_{1}\right)$ was the most influential element in the technology aspect $\left(G_{1}\right)$ and thus needs to be prioritized for enhancement. This is to be followed by technology security $\left(g_{2}\right)$ and technology integration $\left(g_{3}\right)$ (check Figure 2 on the causal relations between $\left(G_{1}\right),\left(G_{2}\right)$, and $\left(G_{3}\right)$ for more details). Each of the assessment elements and aspects comprise the necessities for influencing the Industry 4.0 technology application in SMEs. Therefore, SME managers need to assess all of the aspects and elements for Industry 4.0 technology in accordance with Figure 2. This assessment approach is applicable to most SMEs. Nevertheless, SME managers need to pay attention to the fact that, when using the approach, some modifications exist. The significance level for the nine (9) elements might change based on the characteristic of each firm or industry, and SME managers need to compare the assessment approaches for each Industry 4.0 technology model before determining the best application technique.

Lastly, the value of the gap is 0.258 (i.e., the distance to 0 ) for the finance performance and 0.228 for the business performance for the application of Industry 4.0 technology, as shown in Table 8, demonstrating room for enhancement. From the TOE viewpoint, the technology aspect $\left(G_{1}\right)$, presenting the largest value of the gap of 0.428 for the finance performance and 0.392 for the organization aspect $\left(G_{2}\right)$ in terms of the business performance, needs to be the primary precedence for enhancement if managers of SMEs wish to attain the desired value. For long-term enhancement, managers need systematic and sensible administration, as stated above. With our empirical findings, as formulated in Table 9, we were able to realize the objective of this paper. The assessment pattern for the application of Industry 4.0 technology offered in this research is applicable to most SMEs. However, SME managers must be cautious when using the approach. The importance of the nine (9) elements might change based on different circumstances, and managers need to employ the application of Industry 4.0 technology to explain gaps before developing strategies on the best technology to apply.

Table 9. Scheme of enhancement precedence for Industry 4.0 technology application.

\begin{tabular}{ll}
\hline \multicolumn{1}{c}{ Scheme } & \multicolumn{1}{c}{ Array of Enhancement Precedence } \\
\hline F1: Influence network of aspects & $\left(G_{3}\right),\left(G_{1}\right),\left(G_{2}\right)$ \\
\hline & $\left(G_{1}\right):\left(C_{2}\right),\left(C_{3}\right),\left(C_{1}\right)$ \\
F2: Influence network of elements within individual aspects & $\left(G_{2}\right):\left(C_{5}\right),\left(C_{4}\right),\left(C_{6}\right)$ \\
& $\left(G_{3}\right):\left(C_{9}\right),\left(C_{8}\right),\left(C_{7}\right)$ \\
\hline & Financial performance \\
F3: Array of aspects required to rise to aspired value (through & $\left(G_{1}\right),\left(G_{3}\right),\left(G_{2}\right)$ \\
\cline { 2 - 2 } high to low, via the value of the gap) & Business performance \\
& $\left(G_{2}\right),\left(G_{3}\right),\left(G_{1}\right)$ \\
\hline & Financial performance \\
& $\left(G_{1}\right):\left(g_{2}\right),\left(g_{3}\right),\left(g_{1}\right)$ \\
& $\left(G_{2}\right):\left(g_{4}\right),\left(g_{5}\right),\left(g_{6}\right)$ \\
F4: Array of elements required to rise to aspired value by & $\left(G_{3}\right):\left(g_{7}\right),\left(g_{9}\right),\left(g_{8}\right)$ \\
\cline { 2 - 2 } individual aspects (through high to low, via the value of gap) & Business performance \\
& $\left(G_{1}\right):\left(g_{2}\right),\left(g_{3}\right),\left(g_{1}\right)$ \\
& $\left(G_{2}\right):\left(g_{6}\right),\left(g_{5}\right),\left(g_{4}\right)$ \\
& $\left(G_{3}\right):\left(g_{8}\right),\left(g_{7}\right),\left(g_{9}\right)$ \\
\hline
\end{tabular}

\section{Conclusions}

This paper has examined issues surrounding the application of Industry 4.0 technology, and proposes a beneficial approach for the estimation and choice of elements for Industry 4.0 technology application using the TOE structure. To the best of our knowledge, that is one of the approaches dictating the Industry 4.0 technology application for SMEs in Taiwan. Industry 4.0 technology application is generally limited to certain fields in Taiwan, rather than within multifaceted topics encompassing technology, organization, and environmental 
elements. Therefore, the approach is important for presenting Industry 4.0 technology application findings on SMEs. These contributions are threefold. First, the assessment of Industry 4.0 technology application is a decision-making issue which is composed of multifaceted interactions and dependences. Next, the Industry 4.0 technology application technique is used to assess the performance and significance values that are alternated into the scores of performances. Lastly, a mixed method is devised to determine the hierarchical structure process and interdependence relationships among the Industry 4.0 technology application aspects and elements. Therefore, as the SMEs help to make use of more technological patterns like the research proposes, technological usages ought to be planned to enhance advantages in the target market. This pattern can be used in various kinds of instances to generate distinct results. These results can also support Industry 4.0 technology application to fit target areas.

There are numerous limitations to this study that require further inspection. Primarily, this study was conducted via surveying a comparatively restricted number of specialists. A greater sample could have allowed for a more multifaceted study of assessment methods, which could have generalized the outcomes of the paper. Next, these TOE assessment elements are concluded from prior literature on TOE assessment, which excluded several possible impacts on the Industry 4.0 technology assessment procedure. Future research can apply dissimilar approaches, such as longitudinal or fuzzy theory research, to detect other elements. Lastly, to offer more objective data on the applicability of the future TOE assessment pattern, future research can use specific performance assessments, such as, finance or the economy, and thus demonstrate the practicality of the general assessment context for the business assessment and Industry 4.0 technology application proposed in this paper.

Further research should focus on learning particular clusters or pairs of Industry 4.0 technology application that are more advantageous. As an approach, it can raise awareness on aspects where improvements are necessary. Additionally, different approaches can be applied, such as the entropy technique, to analyze the weights of the elements. Finally, to offer more objective information on the suitability of the stated Industry 4.0 technology application assessment model, future efforts could be made to use data mining approaches, for example, the support vector machine or random forest, to mention the most essential elements and enhance the feasibility of the universal assessment framework. The consequences of future study can then be associated with those stated here.

Author Contributions: Conceptualization, M.-T.L. \& S.-C.C. \& H.-H.C.; Methodology, M.-T.L.; Formal analysis, M.-T.L.; Investigation, M.-T.L.; Writing—original draft, M.-T.L.; Writing—review \& editing, M.-T.L.; visualization, M.-T.L.; supervision, M.-T.L.; project administration, S.-C.C. \& H.-H.C.; funding acquisition, S.-C.C. \& H.-H.C. All authors have read and agreed to the published version of the manuscript.

Funding: This research was not funded.

Institutional Review Board Statement: Not applicable.

Informed Consent Statement: Not applicable.

Data Availability Statement: Not applicable.

Conflicts of Interest: The authors declare no conflict of interest.

\section{References}

1. Raj, A.; Dwivedi, G.; Sharma, A.; Jabbour, A.B.L.D.S.; Rajak, S. Barriers to the adoption of industry 4.0 technologies in the manufacturing sector: An inter-country comparative perspective. Int. J. Prod. Econ. 2020, 224, 107546. [CrossRef]

2. Li, L. China's manufacturing locus in 2025: With a comparison of "Made-in-China 2025" and "Industry 4.0". Technol. Forecast. Soc. Chang. 2018, 135, 66-74. [CrossRef]

3. Lu, Y. Industry 4.0: A survey on technologies, applications and open research issues. J. Ind. Inf. Integrat. 2017, 6, 1-10. [CrossRef]

4. Lu, Y.; Papagiannidis, S.; Alamanos, E. Internet of Things: A systematic review of the business literature from the user and organizational perspectives. Technol. Forecast. Soc. Chang. 2018, 136, 285-297. [CrossRef] 
5. Gardan, J. Additive manufacturing technologies: State of the art and trends. Int. J. Prod. Res. 2016, 10, 3118-3132. [CrossRef]

6. Urbinati, A.; Borges, M.; Chiesa, V.; Frattini, F. Creating and capturing value from Big Data: A multiple-case study analysis of provider companies. Technovation 2019, 84, 21-36. [CrossRef]

7. Nuccio, M.; Guerzoni, M. Big Data: Hell or Heaven? Digital platforms and market power in the data-driven economy. Compet. Chang. 2019, 23, 312-328. [CrossRef]

8. Nosalska, K.; Piatek, Z.M.; Mazurek, G.; Rzadca, R. Industry 4.0: Coherent definition framework with technological and organizational interdependencies. J. Manuf. Technol. Manag. 2020, 31, 837-862. [CrossRef]

9. Fatorachian, H.; Kazemi, H. A critical investigation of Industry 4.0 in manufacturing: Theoretical operationalisation framework. Prod. Plann. Control. 2018, 29, 633-644. [CrossRef]

10. Xu, D.X.; Xu, E.L.; Li, L. Industry 4.0: State of the art and future trends. Int. J. Prod. Res. 2018, 56, 2941-2962. [CrossRef]

11. Pournader, M.; Shi, Y.; Seuring, S.; Koh, S.C.L. Blockchain applications in supply chains, transport and logistics: A systematic review of the literature. Int. J. Prod. Res. 2020, 58, 2063-2081. [CrossRef]

12. Osterrieder, P.; Budde, L.; Friedli, T. The smart factory as a key construct of Industry 4.0: A systematic literature review. Int. J. Prod. Econ. 2020, 221, 107476. [CrossRef]

13. Liao, Y.; Deschamps, F.; Loures, E.D.F.R.; Ramos, L.F.P. Past, present and future of Industry 4.0-a systematic literature review and research agenda proposal. Int. J. Prod. Res. 2017, 55, 3609-3629. [CrossRef]

14. Chiarini, A.; Belvedere, V.; Grando, A. Industry 4.0 strategies and technological developments. An exploratory research from Italian manufacturing companies. Prod. Plann. Control. 2020, 31, 1385-1398. [CrossRef]

15. Schniederjans, D.G.; Curado, C.; Khalajhedayati, M. Supply chain digitalization trends: An integration of knowledge management. Int. J. Prod. Econ. 2020, 220, 107439. [CrossRef]

16. Garay-Rondero, C.L.; Martinez-Flores, J.L.; Smith, N.R.; Caballero Morales, S.O.; Aldrette-Malacara, A. Digital supply chain model in Industry 4.0. J. Manuf. Technol. Manag. 2020, 31, 887-933. [CrossRef]

17. Wang, S.; Wan, J.; Zhang, D.; Li, D.; Zhang, C. Towards smart factory for industry 4.0: A self-organized multi-agent system with big data based feedback and coordination. Comput. Netw. 2016, 101, 158-168. [CrossRef]

18. De Sousa Jabbour, A.B.L.; Jabbour, C.J.C.; Foropon, C.; Godinho Filho, M. When titans meet-Can industry 4.0 revolutionise the environmentally-sustainable manufacturing wave? The role of critical success factors. Technol. Forecast. Soc. Chang. 2018, 132, 18-25. [CrossRef]

19. Dalenogare, L.S.; Benitez, G.B.; Ayala, N.F.; Frank, A.G. The expected contribution of Industry 4.0 technologies for industrial performance. Int. J. Prod. Econ. 2018, 204, 383-394. [CrossRef]

20. Masood, T.; Egger, J. Augmented reality in support of Industry 4.0-Implementation challenges and success factors. Robot. Comput. Integr. Manuf. 2019, 58, 181-195. [CrossRef]

21. Masood, T.; Egger, J. Adopting augmented reality in the age of industrial digitalisation. Comput. Ind. 2020, 115, 103112. [CrossRef]

22. Lin, D.; Lee, C.K.M.; Lau, H.; Yang, Y. Strategic response to Industry 4.0: An empirical investigation on the Chinese automotive industry. Ind. Manag. Data Syst. 2018, 118, 589-605. [CrossRef]

23. Ardito, L.; Petruzzelli, A.M.; Panniello, U.; Garavelli, A.C. Towards Industry 4.0: Mapping digital technologies for supply chain management-marketing integration. Bus. Process Manag. J. 2019, 25, 323-346. [CrossRef]

24. Mariani, M.; Borghi, M. Industry 4.0: A bibliometric review of its managerial intellectual structure and potential evolution in the service industries. Technol. Forecast. Soc. Chang. 2019, 149, 119752. [CrossRef]

25. Lu, M.T.; Hu, S.K.; Huang, L.H.; Tzeng, G.H. Evaluating the implementation of business-to-business m-commerce by SMEs based on a new hybrid MADM model. Manag. Decis. 2015, 53, 290-317. [CrossRef]

26. Liou, J.J.H.; Lu, M.T.; Hu, S.K.; Cheng, C.H.; Chuang, Y.C. A hybrid MCDM model for Improving the Electronic Health Record to Better Serve Client Needs. Sustainability 2017, 9, 1819. [CrossRef]

27. Lu, M.T.; Tzeng, G.H.; Tang, L.L. Environmental strategic orientations for improving green innovation performance in fuzzy environment-Using new fuzzy Hybrid MCDM model. Int. J. Fuzzy Syst. 2013, 15, 297-316.

28. Lu, M.T.; Tsai, J.F.; Shen, S.P.; Lin, M.H. Hu, Y.C. Estimating sustainable development performance in the electrical wire and cable industry: Applying the integrated fuzzy MADM approach. J. Clean Prod. 2020, 277, 122440. [CrossRef]

29. Sevinç, A.; Gür, Ş.; Eren, T. Analysis of the Difficulties of SMEs in Industry 4.0 Applications by Analytical Hierarchy Process and Analytical Network Process. Processes 2018, 6, 264.

30. Çalık, A. A novel Pythagorean fuzzy AHP and fuzzy TOPSIS methodology for green supplier selection in the Industry 4.0 era. Soft Comput. 2020, 23, 1-13. [CrossRef]

31. Braziotis, C.; Rogers, H.; Jimo, A. 3D printing strategic deployment: The supply chain perspective. Supply Chain Manag. 2019, 24, 397-404. [CrossRef]

32. Gress, D.R.; Kalafsky, R.V. Geographies of production in 3D: Theoretical and research implications stemming from additive manufacturing. Geoforum 2015, 60, 43-52. [CrossRef]

33. Ancarani, A.; Di Mauro, C.; Legenvre, H.; Cardella, M.S. Internet of Things adoption: A typology of projects. Int. J. Oper. Prod. Manag. 2020, 40, 849-872. [CrossRef]

34. Castelo-Branco, I.; Cruz-Jesus, F.; Oliveira, T. Assessing Industry 4.0 readiness in manufacturing: Evidence for the European Union. Comput. Ind. 2019, 197, 22-32. [CrossRef] 
35. Doh, S.; Kim, B. Government support for SME innovations in the regional industries: The case of government financial support program in South Korea. Res. Policy. 2014, 43, 1557-1569. [CrossRef]

36. Kusiak, A. Smart manufacturing. Int. J. Prod. Res. 2018, 56, 508-517. [CrossRef]

37. Strozzi, F.; Colicchia, C.; Creazza, A.; Noè, C. Literature review on the 'smart factory' concept using bibliometric tools. Int. J. Prod. Res. 2017, 55, 6572-6591. [CrossRef]

38. Galati, F.; Bigliardi, B. Industry 4.0: Emerging themes and future research avenues using a text mining approach. Comput. Ind. 2019, 109, 100-113. [CrossRef]

39. Frank, G.A.; Dalenogare, L.S.; Ayala, N.F. Industry 4.0 technologies: Implementation patterns in manufacturing companies. Int. J. Prod. Econ. 2019, 210, 15-26. [CrossRef]

40. Sharp, R.; Lopik, K.V.; Neal, A.; Goodall, P.; Conway, P.P.; West, A.A. An industrial evaluation of an Industry 4.0 reference architecture demonstrating the need for the inclusion of security and human components. Comput. Ind. 2019, 108, 37-44. [CrossRef]

41. Yin, Y.; Stecke, K.E.; Li, D. The evolution of production systems from Industry2.0 through Industry 4.0. Int. J. Prod. Res. 2018, 56, 848-861. [CrossRef]

42. Mittal, S.; Khan, M.; Muztoba, A.; Romero, D.; Wuest, T. A critical review of smart manufacturing \& Industry 4.0 maturity models: Implications for small and medium-sized enterprises (SMEs). J. Manuf. Syst. 2018, 49, 194-214.

43. Etemad, H. Internationalization of small and medium sized enterprises: A grounded theoretical framework and an overview. Can. J. Adm. Sci. Rev. Can. Des Sci. L Adm. 2009, 21, 1-21. [CrossRef]

44. European Commission. User Guide to the SME Definition; Publications Office-of-the European Union: Luxembourg, 2016 ; pp. 3-44.

45. Knight, G. Entrepreneurship and marketing strategy: The SME under globalization. J. Int. Mark. 2000, 8, 12-32. [CrossRef]

46. Wallsten, S.J. The effects of government industry R\&D programs on private R\&D: The case of the Small Business Innovation Research program. Rand J. Econ. 2000, 31, 82-100.

47. Brunswicker, S.; Vanhaverbeke, W. Open Innovation in Small and Medium Sized Enterprises (SMEs): External Knowledge Sourcing Strategies and Internal Organizational Facilitators. J. Small Bus. Manag. 2015, 53, 1241-1263. [CrossRef]

48. Kaartinen, H.; Pieska, S.; Vahasoyrinki, J. Digital manufacturing toolbox for supporting the manufacturing SMEs. In Proceedings of the 7th IEEE International Conference on Cognitive Infocommunications, Wroclaw, Poland, 16-18 October 2016; pp. 71-76.

49. Müller, J.; Voigt, K.I. Industry 4.0 for small and medium sized enterprises. Product. Manag. 2016, 21, $28-30$.

50. Moeuf, A.; Pellerin, R.; Lamouri, S.; Tamayo-Giraldo, S.; Barbaray, R. The industrial management of SMEs in the era of Industry 4.0. Int. J. Prod. Res. 2018, 56, 1118-1136. [CrossRef]

51. Vrchota, J.; Volek, T.; Novotná, M. Factors introducing industry 4.0 to SMES. Soc. Sci. 2019, 8, 130. [CrossRef]

52. Rauch, E.; Linder, C.; Dallasega, P. Anthropocentric perspective of production before and within Industry 4.0. Comput. Ind. Eng. 2020, 139, 105644. [CrossRef]

53. Modrak, V.; Soltysova, Z.; Poklemba, R. Mapping requirements and roadmapdefinition for introducing I 4.0 in SME environment. In Advances in Manufacturing Engineering and Materials, Proceedings of the International Conference on Manufacturing Engineering and Materials (ICMEM 2018), Nový Smokovec, Slovakia, 18-22 June 2018; Hloch, S., Klichová, D., Krolczyk, G., Chattopadhyaya, S., Ruppenthalová, L., Eds.; Springer Nature Switzerland AG: Cham, Switzerland, 2019.

54. Fettermann, D.C.; Cavalcante, C.G.S.; Almeida, T.D.D.; Tortorella, G.L. How does Industry 4.0 contribute to operations management? J. Ind. Prod. Eng. 2018, 35, 255-268. [CrossRef]

55. Hofmann, E.; Rüsch, M. Industry 4.0 and the current status as well as future prospects on logistics. Comput. Ind. 2017, 89, 23-34. [CrossRef]

56. Barreto, L.; Amaral, A.; Pereira, T. Industry 4.0 implications in logistics: An overview. Procedia Manuf. 2017, 13, 1245-1252. [CrossRef]

57. Oesterreich, T.D.; Teuteberg, F. Understanding the implications of digitisation and automation in the context of Industry 4.0: A triangulation approach and elements of a research agenda for the construction industry. Comput. Ind. 2016, 83, 121-139. [CrossRef]

58. Ben-Daya, M.; Hassini, E.; Bahroun, Z. Internet of things and supply chain management: A literature review. Int. J. Prod. Res. 2017, 57, 4719-4742. [CrossRef]

59. Haddud, A.; DeSouza, A.; Khare, A.; Lee, H. Examining potential benefits and challenges associated with the Internet of Things integration in supply chains. J. Manuf. Technol. Manag. 2017, 28, 1055-1085. [CrossRef]

60. Mellor, S.; Hao, L.; Zhang, D. Additive manufacturing: A framework for implementation. Int. J. Prod. Econ. 2014, 149, 194-201. [CrossRef]

61. Svan, F.; Lars, M.; Rikard, L. Embracing digital innovation in incumbent firms: How Volvo cars managed competing concerns. MIS Q. 2017, 41, 239-254. [CrossRef]

62. Zangiacomi, A.; Pessot, E.; Fornasiero, R.; Beretti, M.; Sacco, M. Moving towards digitalization: A multiple case study in manufacturing. Prod. Plann. Control. 2020, 31, 143-157. [CrossRef]

63. Tortorella, G.L.; Cawley Vergara, A.M.; Garza-Reyes, J.A.; Sawhney, R. Organizational learning paths based upon Industry 4.0 adoption: An empirical study with Brazilian manufacturers. Int. J. Prod. Econ. 2020, 219, 284-294. [CrossRef]

64. Veile, J.W.; Kiel, D.; Müller, J.M.; Voigt, K.I. Lessons learned from Industry 4.0 implementation in the German manufacturing industry. J. Manuf. Technol. Manag. 2020, 31, 977-997. [CrossRef] 
65. Reynolds, E.B.; Yilmaz, U. Strengthening advanced manufacturing innovation ecosystem: The case of Massachusetts. Technol. Forecast. Soc. Chang. 2018, 136, 178-191. [CrossRef]

66. Sung, T. Industry 4.0: A Korea perspective. Technol. Forecast. Soc. Chang. 2018, 132, 40-45. [CrossRef]

67. Kummitha, R.K.R.; Crutzen, N. Smart cities and the citizen-driven Internet of Things: A qualitative inquiry into an emerging smart city. Technol. Forecast. Soc. Chang. 2019, 140, 44-53. [CrossRef]

68. Fukuda, K. Science, technology and innovation ecosystem transformation toward Society 5.0. Int. J. Prod. Econ. 2020, 220, 107460. [CrossRef]

69. Horváth, D.; Szabó, R.Z. Driving forces and barriers of Industry 4.0: Do multinational and small and medium-sized companies have equal opportunities? Technol. Forecast. Soc. Chang. 2019, 146, 119-132. [CrossRef]

70. Moeuf, A.; Lamouri, S.; Pellerin, R.; Tamayo-Giraldo, S.; Tobon-Valencia, S.; Eburdy, R. Identification of critical success factors, risks and opportunities of Industry 4.0 in SMEs. Int. J. Prod. Res. 2020, 58, 1384-1400. [CrossRef]

71. Arcidiacono, F.; Ancarani, A.; Di Mauro, C.; Schupp, F. Where the rubber meets the road. Industry 4.0 among SMEs in the automotive sector. IEEE Eng. Manag. Rev. 2019, 47, 86-93.

72. Tornatzky, L.G.; Fleischer, M. The Processes of Technological Innovation; Lexington Books: Lanham, MD, USA, 1990.

73. Yeh, C.C.; Chen, Y.F. Critical success factors for adoption of 3D printing. Technol. Forecast. Soc. Chang. 2018, 132, 209-216. [CrossRef]

74. Lu, M.T.; Lin, S.W.; Tzeng, G.H. Improving RFID adoption in Taiwan's healthcare industry based on a DEMATEL technique with a hybrid MCDM model. Decis. Support Syst. 2013, 56, 259-269. [CrossRef]

75. Lu, M.T.; Hsu, C.C.; Liou, J.J.; Lo, H.W. A hybrid MCDM and sustainability balanced scorecard model to establish sustainable performance evaluation for international airports. J. Air Transp. Manag. 2018, 71, 9-19. [CrossRef]

76. Lu, M.T.; Tzeng, G.H.; Cheng, H.; Hsu, C.C. Exploring mobile banking services for user behavior in intention adoption: Using new hybrid MADM model. Serv. Bus. 2015, 9, 541-565. [CrossRef]

77. Saaty, T.L. Decision Making with Dependence and Feedback: The Analytic Network Process; RWS Publications: Pittsburgh, PA, USA, 1996.

78. Opricovic, S.; Tzeng, G.H. Compromise solution by MCDM methods: A comparative analysis of VIKOR and TOPSIS. Eur. J. Oper. Res. 2004, 156, 445-455. [CrossRef]

79. Opricovic, S.; Tzeng, G.H. Extended VIKOR method in comparison with outranking methods. Eur. J. Oper. Res. 2007, 178, 514-529. [CrossRef] 